\title{
Sociedad Cooperativa de Artesanos de Santiago Temoaya, S.L.C.
}

\author{
Martha Izquierdo Muciño
}

Universidad Autónoma del Estado de México

\section{Introducción}

La República Mexicana integrada por 32 Entidades Federativas y un Distrito Federal (Ciudad de México), cuenta aún con muchos pueblos y culturas diversas hacia todas las latitudes que conservan nuestras raíces y nuestro folclor.

El Estado de México es una de las entidades federativas y se encuentra enclavado en el centro del país, rodeando a la capital mexicana. Conserva actualmente una gran cantidad de población indígena, distribuida en distintas zonas y cabeceras municipales como es el municipio de Temoaya.

La razón por la cual nos hemos avocado a la investigación y estudio de uno de sus municipios «Temoaya», es porque en él existe una cooperativa cuyos integrantes son en su mayoría indígenas, que elaboran tapetes anudados a mano (de técnica persa) y que son conocidos internacionalmente.

Este municipio se encuentra ubicado en la parte centro-norte del Estado de México, en las coordenadas $19^{\circ} 28^{\prime} 50^{\prime \prime}$ de latitud norte y $99^{\circ} 36^{\prime} 12^{\prime \prime}$ de longitud oeste, a una altura de 2.680 metros sobre el nivel del mar. Limita al norte con diversas poblaciones como son: Jiquipilco y Nicolás Romero, al sur con Toluca y Otzolotepec, al este con Isidro Fabela, Jocotzingo y Otzolotepec y al oeste con Ixtlahuaca y Almoloya de Juárez. La cabecera municipal esta a $20 \mathrm{kms}$. al noreste de la Ciudad de Toluca. Su territorio asciende a 199,63 km² que equivalen al 0,88\% de la superficie del Estado de México. Cerca de 19.416 
habitantes conservan aún la lengua indígena «otomí» que representa el $37.77 \%$ de su población.

El origen de la cooperativa denominada «Sociedad Cooperativa de Artesanos Productores de Tapetes Anudados a Mano Santiago Temoaya, S.L.C.», fue una empresa privada (1969) que al observar la habilidad artesanal en el ramo textil de los indígenas de ese lugar quiso aprovecharla enseñándoles la técnica de tapetes anudados a mano de origen persa, posteriormente esta empresa desaparece, quedando en manos del gobierno del Estado de México, y finalmente en 1998 se convierte en una cooperativa totalmente independiente hasta la fecha.

Los tapetes que elabora esta cooperativa son reconocidos internacionalmente por su calidad y decoración pero también por sus diseños que proyectan el arte y la cultura de varios Estados de la República y con ello el arte popular mexicano. Por otra parte llama nuestra atención la diversidad de factores que intervienen en la cooperativa como son lo económico, cultural, histórico, religioso, etc., pero fundamentalmente lo social y lo humano, algo que no le es ajeno a esta forma de organización social, toda vez que los anhelos y demandas del grupo étnico "otomí», como es el caso a estudio, conjunta el sufrimiento con la esperanza, el trabajo con la voluntad y la convivencia social con la festiva y religiosa, observándose que se apoyan mutuamente tanto para la celebración de sus fiestas como para la celebración del Santo Patrón del Pueblo que es el Apóstol Santiago, «patrón de España y de Temoaya». ${ }^{1}$

Que en palabras de un entrañable amigo Antonio Colomer dice:

La cooperativa no puede ser sólo una dimensión económica. Si quiere sobrevivir ha de alcanzar en su ámbito interno lo que se ha llamado en otros lugares "una masa critica compleja», es decir, es también un modo de socialización, un proceso de toma de conciencia, un lugar de educación compartida para generar una identidad colectiva y una capacidad de aprendizaje en la participación, un lugar de elaboración de cultura popular, de reconocimiento de símbolos y estilos, una escuela de convivencia no sólo en el trabajo sino también en el ocio, en las artes, en la fiesta y un lugar de consenso

1 Así ha sido reconocido y venerado desde hace muchos siglos atrás. 
fundamental sobre algunos valores que sostienen una ética humanística y propia...2

En los primeros apartados analizamos el origen del grupo «otomí», sus fiestas y tradiciones, su orografía etc., para posteriormente analizar las causas y circunstancias que dieron origen a la conformación de la "Sociedad Cooperativa de Artesanos Productores de Tapetes Anudados a Mano Santiago Temoaya, S.L.C.» su organización y funcionamiento. Finalmente emitimos nuestra opinión acerca de los bondades y desaciertos que se observan, a efecto de dar a conocer esta cooperativa de una manera integral.

\section{Origen de la palabra «temoaya»}

Temoaya proviene del Náhuatl temoayan, que se compone de los vocablos temoa, derivado del verbo temo, que significa «bajar o descender», y de yan, que es el efecto de la acción, por lo tanto temoaya significa «lugar de donde se desciende» o «cuesta abajo»

El glifo correspondiente a este lugar esta compuesto por el ideograma el Tepetl «lugar, sitio o cerro» y el de Otli «camino», que significa; donde las huellas del camino se hayan descendiendo para indicar que se trata de un «lugar de bajada» como a continuación se ilustra.

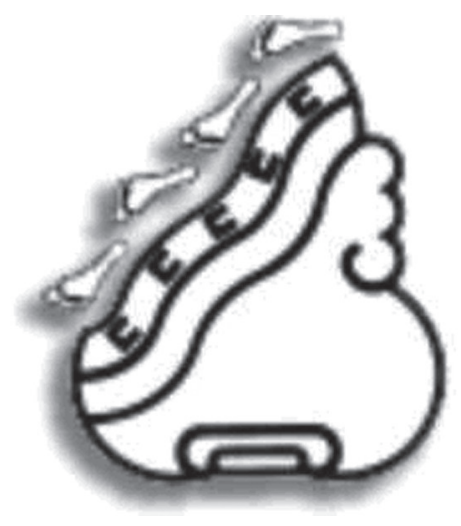

2 Antonio Colomer Viadel: Sociedad Solidaria y Desarrollo Administrativo. FCE. España 1993, p. 362. 
Este lugar de descenso o de bajada, se yergue en el lugar exacto donde la tierra se levanta para señalar el fin de la verde planicie del valle de Toluca y tiene su orgullo de ser el municipio con mayor número de otomíes en el Estado de México, su clima es frío debido a una altitud de 2.680 metros sobre el nivel de mar. ${ }^{3}$

Jesús Arzate Becerril, cronista municipal de Temoaya, cita a Fray Alfonso de Molina para definir esta palabra, en su Arte de la lengua mexicana en la que aborda este término como: «cuesta abajo, o lugar por donde todos descienden», asimismo cita a Peñafiel y a otros autores que sostienen que la palabra es toponográfica, porque geográficamente el lugar corresponde a la toponimia, ya que el pueblo de Temoaya se encuentra en una cuesta o ladera y para salir de él hay que descender.

De hecho menciona que son varios los asentamientos humanos o comunidades en ese lugar que se encuentran ubicados de esta manera y que por tanto para salir tienen que descender a efecto de llegar a la cabecera municipal.

Sostiene el mencionado autor que probablemente durante la dominación Mexicana, a fines del siglo XV, dicho lugar haya sido conocido como Temoaya, sin embargo a principios de la dominación española recibió el nombre de Santa María Asunción, cambiando posteriormente esta denominación para llamarle Santiago Temoaya, uniendo con el nombre a las dos culturas: mexicana y española, lo cual debió ocurrir a fines del siglo XVI a raíz de las congregaciones. ${ }^{4}$

Hoy día los otomíes de la región interpretan el termino temoaya como «lugar donde se reúnen los hermanos».

\section{Contexto histórico-político}

La presencia humana en Temoaya data de la época prehistórica, ya que así lo demuestran diversos vestigios arqueológicos como uten-

3 EnCIClopedia de los municipios del Estado de México: Centro Nacional de Desarrollo Municipal. Gobierno del Estado de México. http//:www.e_local.gob.mx/work/tamplates/enciclo/México/mpios/15087. . .htm

4 Arzate Becerril, Jesús: Temoaya, Monografía municipal. Instituto Mexiquense de Cultura AMECROM. México. H. Ayuntamiento de Toluca, Estado de México (1999),.p. 120. 
silios, herramientas, figuras humanas y los restos de mamut encontrados en los alrededores del municipio.

Algunos autores afirman que los otomíes pueden considerarse como los primeros habitantes de aldeas, villas y ciudades en el centro de México.

Los vestigios con que se cuenta denotan que el pueblo de Temoaya surgió como una división del pueblo de Xiquipilco a raíz de la conquista emprendida por los aztecas a fines del siglo XV.

El primer contacto con los españoles ocurrió hacia 1521 cuando Gonzalo de Sandoval emprendió la conquista de Matlazinco, poco después Fray Alonso Antonio Rangel inició la evangelización de los otomíes y Xiquipilco quedó bajo la advocación del Apóstol Santiago. Por esa época este pueblito empezó a contar con su propio cabildo, además fue concedido en encomienda a Pedro Núñez, Maese de Roa, quien inició el reparto de tierras a los españoles con los que mas tarde habrían de fundar las primeras haciendas. ${ }^{5}$

El primer ayuntamiento constitucional de Temoaya se erigió en 1820 con base en la Constitución de Cádiz y mas adelante dentro del marco de la Federación de 1824 los nacidos de ese lugar pudieron elegir anualmente a sus representantes.

En el siglo xx durante la etapa revolucionaria (1910), Temoaya sufrió el acecho de diversos grupos armados que saquearon comercios y destrozaron sus casas y otros desmanes. Pero una vez pasado el conflicto las autoridades se dieron a la tarea de reconstruir su municipio que le permitió su desarrollo.

Temoaya aún conserva el encanto de las poblaciones del siglo pasado, las viejas casonas que rodean la plaza municipal cuentan con grandes muros de acabados con vigas y techos de tejas rojas.

Es considerado actualmente como la patria del pueblo otomí por ser el municipio con mayor numero de habitantes de esta etnia en el Estado de México. ${ }^{6}$

5 Pueblos Indígenas de México, Serie Monografías. http://www.pueblosindigenasdemexico.com

619.416 habitantes hablan lengua indígena, lo que representa un 37,77\% de la población. 
En 1980 el gobierno del Estado de México, consciente de la importancia histórica de este grupo social erigió el Centro Ceremonial Otomí como un monumento destinado a preservar las tradiciones y rescatar la identidad de este pueblo. ${ }^{7}$

\section{Folklore y artesanía}

Una de las fiestas mas importantes es la del apóstol Santiago, que se celebra el 25 de julio, con casi todas las comunidades del municipio, en medio de practicas religiosas y profanas que incluyen música, flores, incienso, danzas de apaches y santiagueros, ofrendas, velas, portadas florales para los templos, cohetes, globos aerostáticos, fuegos artificiales, procesiones, juegos mecánicos, comercio ambulante, baile y feria.

La imagen ecuestre del Señor «Santiago» constituye en su género, una escultura única en Latinoamérica por su antigüedad y tamaño colosal. Es una verdadera reliquia de arte indígena colonial, cuya técnica de elaboración es de origen prehispánico. ${ }^{8}$ Se trata de la clásica representación del Apóstol Santiago Matamoros que muestra a un guerrero medieval a caballo en actitud de combate.

Temoaya es uno de los pocos lugares en donde se practica la charrería a campo traviesa, comienza a partir del 24 de junio y finaliza a fines de octubre.

El tianguis o mercado tradicional de los domingos conserva sus reminiscencias prehispánicas al igual que la vestimenta de las mujeres otomíes que acuden al mismo. En él se encuentran los famosos chincuetes $^{9}$, fajas, morrales y sarapes elaborados en telares rudimentarios también de herencia prehispánica, lo cual constituye una expresión autentica del arte otomí que vino a enriquecerse posteriormente con el bordado y deshilado de herencia hispana, pero sobre todo con la técnica del anudado a mano como los famosos «tapetes temoaya» que han sido catalogados entre los mejores del mundo por su incomparable calidad y diseños originales, que reflejan la expresión de un pueblo lleno de historia y tradiciones.

7 ReYes PrISCILIANo, Karina: «Panorama histórico de temoaya», Revista de información y difusión cultural. México. año 1, núm. 3 (2006), p. 26

8 Elaboración que incluye una argamaza a base de maíz.

9 Faldas de lana de vistosos colores y tejidos originales de arte indígena. 
Se encuentra también una gran variedad de frutas frescas de la región como los capulines, los nanches, las chirimoyas etc. los hongos de monte, ajolotes, longaniza y el tradicional pulque constituyen otra variedad gastronómica, además se puede disfrutar de la barbacoa de carnero y los charales. En general la gastronomía temoayense incluye platillos como el pipían, sopa de medula, mishiote de carnero y mole de olla. ${ }^{10}$

\section{Origen de los tapetes anudados a mano y nacimiento de una cooperativa}

La habilidad manual de los artesanos indígenas otomíes de Temoaya, en el ramo textil ha logrado plasmar a través del color y la forma una rica y variada artesanía mexicana desde la época prehispánica hasta la actualidad, empleando materiales textiles y minerales, fibras vegetales y animales, produciendo los famosos tejidos como el huipil, el quechquemitl, ayates, fajas y chincuetes hechos en talleres rudimentarios de herencia prehispánica.

Estas capacidades manuales motivaron que en el año de 1969 existiera una inversión de particulares para fundar una empresa denominada: «Tapetes mexicanos de Temoaya», patrocinada por el Banco de México, con el objetivo de crear fuentes de empleo para la región.

Posteriormente en 1974 tapetes mexicanos crea sus instalaciones en San Pedro Abajo, primera sección, lugar que conserva hasta la actualidad, pero el 14 de abril de 1975 se registra como Sociedad Cooperativa de Artesanos Productores de Tapetes Anudados a Mano Santiago Temoaya, S.C.L.

En 1990 la Sociedad Cooperativa deja de ser patrocinada por el Banco de México, pasando a manos del gobierno del Estado de México, y en 1998 la Sociedad paso a ser totalmente independiente, aunque el terreno en donde se encuentran las instalaciones sigue perteneciendo al Estado. ${ }^{11}$

10 Arzate Becerril, Jesús: " "Señor Santiago", Patrón de España y de Temoaya». Revista de información y difusión cultural. México, año 1, núm. 2 (2006), p. 18.

11 «Sociedad cooperativa de artesanos productores de tapetes anudados a mano Santiago Temoaya, S.C.L.», Revista de información y difusión cultural. México, año 1, núm. 1 (2006), p. 19. 
La elaboración de tapetes de lana estilo persa, anudados a mano, son de demanda nacional e internacional. Originalmente la empresa «Tapetes Mexicanos» agrupaba a cerca de 300 artesanos. Actualmente como empresa cooperativa ha reducido ese número, pero una gran cantidad de artesanos de la región trabajan en talleres familiares en forma independiente.

La sociedad cooperativa cuenta con diversas áreas para la elaboración del tapete: una tienda donde se entrega el material, un espacio de lavado y cepillado y el espacio de atención a clientes en donde se expone una gran variedad de tapetes para su compra.

La mayoría de los artesanos, muchos de ellos distribuidos en instalaciones y unidades familiares son del sexo femenino y de edad principalmente adulta, pues una de las problemáticas de la cooperativa es conseguir socios, toda vez que los jóvenes de la región prefieren ir al centro de la republica (Distrito Federal) o al extranjero (Estados Unidos de Norteamérica) a trabajar, como consecuencia del problema de la emigración que se sufre en casi todo el país.

Para la fabricación de un metro cuadrado de tapete se realizan 140 mil nudos, requiriendo de 45 días. El hilo con que se elabora es de lana virgen importado de Argentina y Nueva Zelanda.

La cooperativa hace la venta en sus instalaciones de manera directa o en expoferias que se realizan al interior de la República Mexicana.

Esta artesanía ha impactado en su mayoría a extranjeros, artistas, empresarios y políticos, etc., quienes frecuentemente compran por grandes cantidades para revender en otros países, razón por la cual se ha dado a conocer a nivel internacional.

Los tapetes temoayenses son de alta calidad, duración y belleza, la sociedad cooperativa ofrece una garantía de 24 años de duración, colocando una etiqueta que contiene el número de serie, fecha y año en que fue adquirida. En opinión de algunas personas llegan a superar la calidad persa.

Los diversos diseños de tapetes anudados a mano que elabora la «Sociedad Cooperativa de Artesanos Productores de Tapetes Anudados a Mano Santiago Temoaya, S.L.C.», son estilos típicos de gru- 
pos étnicos de México como el Otomí, Huichol, Mazahua, Papantla, Mexica, Cora, Tepehua, y Chinanteco entre otros.

El diseño otomí representa la flora y la fauna de la cultura, utilizan grecas que alternan pájaros, símbolos mitológicos del dios sol, combinados con flores y figuras geométricas como el rombo, este tapete logra caracterizar las figuras de aves y conlleva una delicada sección de los elementos naturales.

El diseño nayarit es un hermoso diseño sencillo por sus elementos, una estrella estilizada de ocho puntas y la flor llamada loto, en representación del peyote utilizado en las fiestas religiosas del grupo huichol; este motivo se toma de la vestimenta para la gran celebración de la gran fiesta del peyote, en ella le agradecen que los pongan en contacto con sus dioses, el centro de la estrella manifiesta la comunicación de los dioses con los huicholes.

El diseño cora procede del grupo étnico que habita al norte de Nayarit. Cercanos a los huicholes, ambos conglomerados tienen semejanzas: los sistemas decorativos obedecen a concepciones mágico-religiosas cuyo simbolismo representa el esfuerzo por dominar las fuerzas naturales.

El diseño mazahua extrae su estilo de un morral típico de la etnia, pieza utilizada por hombres y mujeres para guardar y acarrear sus pertenencias. Representa aspectos florales que forman cuatro ejes unidos por pares de un centro común. Asimismo, estrellas y flores se entrelazan, la sencillez de su diseño se presenta para todo tipo de decoración, especialmente para las modernas.

En el tapete diseño artesanía organiza una composición dentro de un marco de grecas múltiples cuyo elemento principal es el pájaro, que en la decoración otomí simboliza al dios Sol. Figuras zoomorfas y fitomorfas proceden del hábitat y de las concepciones mágico-religiosas de los indígenas. En éste, el vigoroso juego de colores se emplea con audacia y gran refinamiento.

El tapete diseño mazateco ha recibido diversas influencias culturales predominando los mixtecos y zapotecos, sus patrones estéticos han sufrido cambios, como los huipiles tradicionales, anteriormente tejidos y bordados en su totalidad y que hoy solo lo son en parte, resultando el tejido el complemento de la pieza. En el diseño mazateco se juega con dos colores sobre fondo uniforme, la composición orga- 
nizada sobre líneas longitudinales y una figura central que es un desarrollo vegetal. Complicado y fino, es enriquecido con figuras de pájaros y palomas. ${ }^{12}$

Todos los tapetes anteriores producidos por la Sociedad Cooperativa se caracterizan por plasmar las figuras geométricas, los símbolos mitológicos, los animales típicos, los elementos de la naturaleza y, sobre todo, los colores de cada etnia, aunque también anuda logos de empresas, universidades, equipos de fútbol y nombres de personas $u$ objetos, entre otros diseños.

\section{Organización de la cooperativa}

En el año de 1998, año en que la cooperativa paso a ser independiente, Rufino Bermúdez Bernal funge como primer presidente, terminando su cargo el 6 de octubre de 2004. Actualmente funge como presidente Antonio Gutiérrez Hernández. Cabe decir que estas personas son socios cooperativistas oriundos de la región, con escasos conocimientos en el campo de la administración para el manejo de las cooperativas, aun cuando cuentan con el apoyo del Gobierno del Estado de México que a través del Instituto de Fomento de las Artesanías Mexiquenses les brindan todo tipo de información para el manejo de la cooperativa. Habida cuenta de que esta empresa ha dado a conocer internacionalmente al Estado de México a través del «Tapete Temoayense» como comúnmente se le conoce y con ello la milenaria cultura Otomí, así como la sensibilidad artística y artesanal del arte popular mexicano, por la cual lejos de ser simplemente una empresa cooperativa mas sujeta a los vaivenes de la oferta y la demanda de la actual situación que impera en el mercado mundial como consecuencia de la globalización, realmente es una de las representaciones del Estado de México y su cultura ante el mundo, lo cual es digno de elogio.

Actualmente, junto con Antonio Gutiérrez Hernández (segundo Presidente), Elvia Hernández Medina funge como tesorera, y Tomas Bermúdez Damián como secretario, quienes por voluntad unánime de sus compañeros cooperativistas repiten en su encargo para terminar en este año 2007, siendo uno de los logros de esta administración la

12 Reyes Prisciliano, Karina: nota 6, op. cit., p. 20. 
integración de la cooperativa a la Federación Mexicana de Artesanos, A.C. (FEMART).

Respecto de los Fondos que menciona la Ley General de Sociedades Cooperativas ${ }^{13}$ en el artículo 53, se observa que actualmente sólo manejan el fondo de reserva, no así con el de Previsión Social ni el de Educación Cooperativa, ya que por otra parte tampoco son obligatorios en dicha legislación. De este Fondo de Reserva, se aparta sólo un $5 \%$ de las ganancias que se obtienen (no así el 10\% mínimo a que obliga la ley en el artículo 54), y como tienen que solventar sus gastos y abastecer de materia prima a la cooperativa para la fabricación del tapete, este es reconstituido constantemente.

Se reúnen los socios cada 6 meses y en asamblea general se les informa del grado de avance o retroceso que lleva la cooperativa. Elvia Hernández (Tesorera) menciona que actualmente la cooperativa ha ido progresando a diferencia de la anterior administración que solo reportó perdidas.

La participación de cada uno de sus integrantes resulta muy dinámica ya que se interesan por el estado actual de la cooperativa y asumen sus responsabilidades, se saben dueños de su fuente de trabajo y les preocupa el futuro que pueda tener, ya que para muchos es la primera vez que participan en una experiencia de esta naturaleza.

El reparto de los beneficios obtenidos se hace de acuerdo a las aportaciones o grado de avance del trabajo de cada socio y anualmente conforme lo dispuesto en el artículo 62 de la ley en mención, evaluando sus activos y en Asamblea General en la que se cita a todos los socios cooperativistas, se determina en relación con los incrementos habidos durante el año, el porcentaje que se destina tanto al incremento del capital social como el que se aplica a la reserva social.

Se lleva un libro por separado en el que se encuentra inscrito el nombre y el domicilio de cada uno de los socios, con indicaciones claras sobre sus aportaciones y sus avances. Este libro queda a cargo de los administradores actuales, quienes dan fe de la autenticidad y exactitud de sus datos.

13 Publicada en el «Diario Oficial de la Federación» el día 3 de agosto de 1994. 
Como puede observarse esta organización social asesorada por el Instituto de Fomento de las Artesanías del Estado de México, intenta seguir a grandes rasgos los pasos que deben darse para su buen funcionamiento conforme a la Ley General de Sociedades Cooperativas, tratando de dar cabal cumplimiento a sus lineamientos, lo cual aun cuando es insuficiente dada la precaria preparación de estas personas, vale el esfuerzo que realizan, intentando cumplir los fines de solidaridad y apoyo mutuo, que caracteriza a estas formas de organización social.

\section{Situación actual}

Por desgracia quienes se han enriquecido con los famosos tapetes anudados a mano no han sido ni la cooperativa ni los artesanos del lugar sino quienes se lucran con los tapetes como son los intermediarios que los «revenden» en diversas partes de México y del mundo, algo que sucede frecuentemente en todas partes. Sin embargo se observa que esta región caracterizada por la venta del «tapete Temoayense» ha mejorado en parte su calidad de vida, aunque no lo suficiente, pese al gran esfuerzo que realizan especialmente las mujeres indígenas.

En efecto, de la dura situación de la mujer otomí, han escrito Patricia Molinar Palma y Martha Rebeca Herrera en su libro «Mujer Otomí, La jornada interminable de una vida alfombradamente áspera», en la que narran a través de su contenido resumido de manera literaria y a través de imágenes creadas por la escritura, las estrategias de sobrevivencia que siguen las mujeres otomíes desvelando una realidad lacerante de una vida laboral y cotidiana de las tejedoras del tapete.

Estas investigadoras de la Escuela Nacional de Antropología e Historia (ENAH) dan cuenta de aspectos sobre la salud de las trabajadoras, de sus familias, anhelos, y sufrimientos en sus interminables jornadas de trabajo, toda vez que se trata de una de tantas poblaciones vulnerables, de pueblos indígenas de los muchos que existen en nuestro país.

No obstante lo anterior podemos afirmar que estas mujeres se sienten satisfechas de poder contar con una fuente de empleo de la que se consideran integrantes toda vez que son tomadas en cuenta tanto para la rendición de cuentas como para la elección de sus repre- 
sentantes, y que además les permite contar con un pequeño ingreso para ellas y sus familias.

Por otra parte saben bien que el interés por sus productos no solo es económico sino también social y cultural y que a través del arte plasmado en sus tejidos han logrado atraer al turismo nacional y extranjero, a investigadores y a estudiosos de sus culturas, usos y costumbres, lo que ha dado lugar a una gran cantidad de información publicada al respecto.

Su carácter social y amable nos permite observar que se sienten orgullosas de su cultura milenaria, de la indumentaria tradicional que portan, de su arte otomí y de sus famosos tapetes anudados a mano, porque saben bien que han sido reconocidos en todo el mundo como de los mejores tanto por su técnica (de origen persa) como por el estilo que han logrado plasmar en ellos, que refleja el arte de todo el país.

\section{VIII. Últimas reflexiones}

Los planteamientos aquí vertidos sobre el desarrollo de la cooperativa de tapetes anudados a mano, en la región otomí, resulta un poco complejo, ya que como hemos visto existen varias dimensiones de esta sociedad económica: la social, cultural etc. Sin embargo bajo la dimensión territorial como cultura autóctona, el enfoque económico toma un lugar preponderante dentro de sus demandas y de sus aspiraciones, cuyos propósitos de vida deberían permitir vincular de manera óptima la oferta de recursos existentes con nuevas promociones para un desarrollo más exitoso.

Se dice que las experiencias «desde abajo» deben entrar en los Planes y Programas de desarrollo por parte del Estado, pero por otra parte se plantean algunas interrogantes, una de ellas es que en dónde se establecen los límites entre las formas de organización social autónomas como las cooperativas y la movilización del Estado, que implica el peligro de control estatal.

Por otra parte es necesario el establecimiento de condiciones favorables para el surgimiento de desarrollo "desde abajo», para todas las formas tradicionales de organización que satisfagan las demandas auténticas de los sectores populares, dada la difícil situación que se vive 
en el país (marginación, desempleo, pobreza, etc.) como consecuencia de las políticas económicas de exclusión que en los últimos años han sido adoptadas por nuestros gobiernos.

Todos estos obstáculos debieran ser superados por modelos alternativos de producción económica, cuya autonomía financiera es imprescindible para sus niveles de planificación y decisión democrática.

Si bien la cooperativa no sólo es una dimensión económica como se ha mencionado sino una toma de conciencia y de convivencia no sólo en el trabajo, sino también en el ocio, en las fiestas etc., esto es, "una masa crítica compleja», en consecuencia se requiere que esa «masa crítica compleja» tenga una proyección externa, estableciendo una red con otras empresas comunitarias y cooperativas del sector a todos los niveles, para alcanzar un punto de resistencia y no de retorno y una capacidad multiplicadora en el manejo de insumos, en los métodos de asistencia técnica y en el acceso a recursos financieros, pero ante todo hay que insistir en la importancia de la educación comunitaria.

En efecto, la educación cooperativa y comunitaria debe iniciarse desde la escuela primaria, estableciendo un marco jurídico flexible y adaptado a las necesidades de cada localidad, evitando los paternalismos estatales que concentran demasiados poderes discrecionales, al grado de una tutela inadmisible.

Para finalizar retomamos las palabras de Juan Guillermo Espinoza que menciona:

La búsqueda de una nueva sociedad en donde el ser humano sea el centro de desarrollo, parece emerger con mas fuerza que antes. Las mismas amenazas o realidades que se enfrentan de aniquilación nuclear, de creciente concentración del poder y la fuerza, de dictadura y militarismos en reemplazo de la razón y la democracia, de las libertades irrestrictas al mercado y al capital mientras se restringen las libertades de las personas y de las organizaciones sociales, parecen no haber hecho mas que reforzar la búsqueda de una nueva sociedad y una nueva economía en donde la condición humana sea realzada. ${ }^{14}$

14 Colomer Viadel, Antonio (coord.): «Sociedad Solidaria y Desarrollo Alternativo», t. III: Economía, Autogestión y Desarrollo. España. Fondo de Cultura Económica (1993), p. 76. 


\section{Fuentes}

1. Enciclopedia de los municipios del Estado de México. Centro Nacional de Desarrollo Municipal. Gobierno del Estado de México http//:www.e_local. gob.mx/work/tamplates/enciclo/México/mpios/15087. ${ }^{a}$.htm

2. Arzate Becerril, Jesús: Temoaya, Monografía Municipal. Instituto Mexiquense de Cultura AMECROM. México. H. Ayuntamiento de Toluca, Estado de México (1999.

3. Pueblos Indígenas de México, Serie Monografías. http://www.pueblosindigenasdemexico.com

4. ReYes PrISCILIANo, Karina: "Panorama histórico de temoaya». Revista de información y difusión cultural. México, año 1, núm. 3 (2006).

5. Arzate BecerriL, Jesús: "Señor Santiago", Patrón de España y de Temoaya». Revista de información y difusión cultural. México, año 1, número 2 (2006).

6. «Sociedad cooperativa de artesanos productores de tapetes anudados a mano Santiago Temoaya, S.C.L.», Revista de información y difusión cultural. México, año 1, núm 1 (2006).

7. Colomer Viadel, Antonio (coord.): Sociedad Solidaria y Desarrollo Alternativo, t. III: Economía, Autogestión y Desarrollo. España. Fondo de Cultura Económica (1993).

8. Molinar, Patricia y HerReRA, Martha Rebeca: La jornada interminable de una vida alfombradamente áspera». México. Escuela Nacional de Antropología e Historia ENAH (2006).

9. Ley General de Sociedades Cooperativas. México 2000. Editorial Porrúa. 